\title{
An investigation into the rates of transmission of SARS-CoV-2 during the first 6 weeks of the 2020-2021 academic year in primary and post-primary schools in Cork and Kerry, Ireland
}

\author{
Philippa White ${ }^{1} \mathbb{D} \cdot$ Margaret Bernadette O'Sullivan ${ }^{1} \cdot$ Nicola Murphy ${ }^{1} \cdot$ Jane Stapleton ${ }^{1}$. Annette Dillon ${ }^{1}$. \\ Aline Brennan ${ }^{1} \cdot$ Benvon Deasy ${ }^{1} \cdot$ Louise Carlton $^{1} \cdot$ Áine Bermingham ${ }^{1} \cdot$ Mary Teresa O'Mahony $^{1} \cdot$ Deirdre Murray $^{1}$. \\ Cliodhna Foley Nolan ${ }^{1} \cdot$ Anne Sheahan ${ }^{1}$
}

Received: 5 January 2021 / Accepted: 26 February 2021 / Published online: 1 April 2021

(c) Royal Academy of Medicine in Ireland 2021

\begin{abstract}
Background Schools in Ireland closed in March 2020 as part of a national strategy to contain the spread of severe acute respiratory syndrome (SARS-CoV-2). The extent to which schools contribute to the overall propagation of SARS-CoV-2 was continuing to evolve internationally.

Aims To examine regional data on SARS-CoV-2 transmission in primary, post-primary and special schools in Cork and Kerry, two counties in southwest Ireland, during the first 6 weeks of the 2020-2021 academic year and determine the rate of in-school transmission.

Methods Data were obtained from the Computerised Infectious Disease Reporting (CIDR) system and supplemented with digital records from the regional Department of Public Health (Dept PH) and from the Health Service Executive (HSE) Covid Care Tracker application. The positivity rate among school close contacts was calculated to determine the rate of in-school SARS-CoV-2 transmission.

Results The overall rate of in-school transmission of SARS-CoV-2 was low at $4.1 \%$. Positivity rates among students and staff who were close contacts were similarly low (3.1\% vs. 6.9\%, $p=0.07)$. One secondary case of coronavirus disease 2019 (COVID-19) emerged, on average, for every 7.6 infectious days spent by an index case in school. Schools accounted for $2.2 \%$ of all notified cases of COVID-19 in the region during the observation period.

Conclusions During the first 6 weeks of the academic year, the rate of in-school SARS-CoV-2 transmission in the region was low, and schools did not contribute substantially to the overall burden of COVID-19.
\end{abstract}

Keywords COVID-19 $\cdot$ Outbreaks $\cdot$ SARS-CoV-2 $\cdot$ Schools

\section{Introduction}

On March 12, 2020 all primary, post-primary and special schools in Ireland were closed as part of a broad national strategy to contain the spread of severe acute respiratory syndrome (SARS-CoV-2) [1]. In July 2020, the Department of Education, informed by public health advice and engagement with educational stakeholders, devised a roadmap for

Philippa White

philippa.white2@hse.ie

1 Department of Public Health, HSE South, St Finbarr's Hospital, Douglas, Cork, Ireland the reopening of schools in Ireland [2], and schools across the country subsequently reopened in late August 2020.

Following their reopening, many infection prevention and control (IPC) measures to prevent and limit the spread of SARS-CoV-2 in school settings were implemented. These included the use of facial coverings for staff and students aged 13 years and older where $2 \mathrm{~m}$ physical distance could not be maintained, the maintenance of at least $1 \mathrm{~m}$ distance between students in classrooms (except for students in the first 4 years of primary school), adherence to hand hygiene and the implementation of enhanced cleaning regimes, among many other measures [3, 4]. Efforts have been made by the Department of Education to ensure that schools can remain safely open through the issuing of guidance documents and the provision of monetary and non-monetary supports [2]. 
The eight regional Departments of Public Health (Depts $\mathrm{PH}$ ) in Ireland play a key role in preventing and limiting the spread of SARS-CoV-2 in schools by rapidly identifying cases of coronavirus disease 2019 (COVID-19) and their close contacts in schools, ensuring close contacts are tested for COVID19 and advising on isolation and restricted movement periods, as necessary, for the required time periods. Furthermore, the regional Depts PH advise individual schools on actions to mitigate the risk of transmission of SARS-CoV-2 in a particular school setting where applicable [5].

Cork and Kerry, hereafter referred to as HSE (Health Service Executive) South, have a combined population of over 690,000 [6], representing approximately $14 \%$ of the total population of the Republic of Ireland [7]. A total of 134,515 pupils are enrolled in schools in HSE South, with 79,564 students in 430 primary schools, 53,788 students in 82 postprimary schools, and 1163 students in 18 special schools [8-10]. Special schools are schools which provide education for children with special educational needs. The Dept PH HSE South is notified of all regional cases of COVID-19.

The aim of this study was to examine the rate of in-school transmission of SARS-CoV-2 in primary, post-primary, and special schools in HSE South during the first 6 weeks of the 2020-2021 academic year and to determine the extent to which schools contributed to the overall burden of COVID19 in the region during this period.

\section{Methods}

Onward transmission of SARS-CoV-2 in primary, postprimary and special schools in HSE South during the first 6 weeks of the academic year (27 August-11 October 2020) was investigated. As the date of school reopening after summer holidays in Ireland is not standardised [11], this time period included an extra week for some schools.

An index case was defined as the first individual to be identified with COVID-19 in a school or class grouping, with the first positive COVID-19 polymerase chain reaction (PCR) test result or the earliest symptom onset, and an infection source outside the school. For the purpose of this study, only index cases that were notified to the Dept PH during the observation period, attended school during his or her infectious period, and had close contacts in school identified by contact tracing were included. Index cases that had no close contacts in school identified by contact tracing were excluded. Relevant epidemiological data were collated on every student and staff index case of COVID-19 who met these eligibility criteria. A case's infectious period was defined as (a) the period starting 48 hours prior to symptom onset and ending 10 days after symptom onset for symptomatic cases or (b) starting 24 hours prior to a positive test and ending 10 days after the positive test for asymptomatic cases [12].
Data on the index case's age, role (e.g. student or teacher), school attendance during his or her infectious period, symptoms and names of school close contacts were all collected. A close contact was defined as an individual who was within $1 \mathrm{~m}$ of a case of COVID-19 while wearing a mask, or within $2 \mathrm{~m}$ if unmasked, in an indoor or outdoor setting for a cumulative total of $15 \mathrm{~min}$ or more over a 24-hour period during the case's infectious period. The results of all identified school close contacts' COVID-19 PCR tests, taken within the 14-day period after the last exposure to the index case, were examined to determine the rate of in-school transmission.

Where a school close contact tested positive, the COVID19 PCR test results of their school, household and social close contacts in turn were examined to assess whether further transmission had occurred. This process was repeated to assess the extent to which further transmission had subsequently occurred in school and beyond the school setting, and to determine the extent to which schools contributed to the overall burden of COVID-19 in the region during this time period.

An in-depth epidemiological investigation into every school case which emerged was conducted and where there was evidence that a staff or student close contact was more likely to be infected outside of school than in school (e.g. if a family member had already tested positive), they were not reported to have been infected in school.

Data on student and staff index cases were obtained from the Computerised Infectious Disease Reporting (CIDR) system, the primary information system developed to manage the surveillance and control of infectious diseases in Ireland [13]. They were supplemented with more detailed information from the Dept PH's digital records of cases of COVID19 in schools and from information retrieved from the HSE Covid Care Tracker application, a national online system in which information about every confirmed case of COVID-19 in Ireland is recorded.

Fisher's exact test was performed to compare COVID-19 positivity rates of students and staff close contacts. All statistical analyses were conducted using Stata version 15 [14].

\section{Results}

Overall, there were 1614 confirmed cases of COVID-19 notified in HSE South during the observation period, 199 $(12.33 \%)$ of whom were children of school-going age (i.e. 4-18 years) and 1141 (70.7\%) of whom were adults of working age (i.e. 19-65 years). Over that time, 62 index cases of COVID-19 (students and staff) were identified as having attended schools in the region during their infectious period and had close contacts in school identified by contact tracing. Of these 62 index cases, $80.6 \%(n=50)$ were students and $19.4 \%(n=12)$ were staff (Table 1$)$. 
Table 1 Characteristics of the index cases in schools who tested positive for COVID-19, attended school during their infectious period and had close contacts in school in HSE South, Ireland, 27 August-11 October $2020(n=62)$

\begin{tabular}{|c|c|c|c|}
\hline Role of index case & $\begin{array}{l}\text { Total cases } \\
(\mathrm{n}=62)(\%)\end{array}$ & $\begin{array}{l}\text { Student cases } \\
(\mathrm{n}=50)(\%)\end{array}$ & $\begin{array}{l}\text { Staff cases } \\
(\mathrm{n}=12) \\
(\%)\end{array}$ \\
\hline Students & $50(80.6 \%)$ & $\mathrm{n} / \mathrm{a}$ & $\mathrm{n} / \mathrm{a}$ \\
\hline Staff & $12(19.4 \%)$ & $\mathrm{n} / \mathrm{a}$ & $\mathrm{n} / \mathrm{a}$ \\
\hline \multicolumn{4}{|l|}{ Type of school } \\
\hline Primary & $32(51.6 \%)$ & $24(48 \%)$ & $8(66.7 \%)$ \\
\hline Post-primary & $27(43.6 \%)$ & $24(48 \%)$ & $3(25 \%)$ \\
\hline Special & $3(4.8 \%)$ & $2(4 \%)$ & $1(8.3 \%)$ \\
\hline \multicolumn{4}{|l|}{ Age group of index case } \\
\hline $4-12$ years & $27(43.5 \%)$ & $27(54 \%)$ & 0 \\
\hline $13-18$ years & $23(37.1 \%)$ & $23(46 \%)$ & 0 \\
\hline$\geq 19$ years $^{\mathrm{a}}$ & $12(19.4 \%)$ & 0 & $12(100 \%)$ \\
\hline \multicolumn{4}{|l|}{ Symptoms of index case } \\
\hline Symptomatic & $56(90.3 \%)$ & $44(88 \%)$ & $12(100 \%)$ \\
\hline Asymptomatic & $6(9.7 \%)$ & $6(12 \%)$ & 0 \\
\hline \multicolumn{4}{|l|}{$\begin{array}{l}\text { Length of time index case attended school during } \\
\text { infectious period }\end{array}$} \\
\hline 1-2 days & $35(56.4 \%)$ & $28(56 \%)$ & $7(58.3 \%)$ \\
\hline 3-4 days & $20(32.3 \%)$ & $15(30 \%)$ & $5(41.7 \%)$ \\
\hline 5-6 days & $7(11.3 \%)$ & $7(14 \%)$ & 0 \\
\hline \multicolumn{4}{|l|}{ Number of school close contacts per case } \\
\hline $1-5$ close contacts & $40(64.5 \%)$ & $33(66 \%)$ & $7(58.3 \%)$ \\
\hline $6-10$ close contacts & $14(22.6 \%)$ & $11(22 \%)$ & $3(25 \%)$ \\
\hline$>10$ close contacts $^{\mathrm{b}}$ & $8(12.9 \%)$ & $6(12 \%)$ & $2(16.7 \%)$ \\
\hline \multicolumn{4}{|l|}{ Source of infection } \\
\hline Close contact with family & $18(29 \%)$ & $17(34 \%)$ & $1(8.3 \%)$ \\
\hline Close contact with person outside of family & $15(24.2 \%)$ & $12(24 \%)$ & $3(25 \%)$ \\
\hline Travel-related & $2(3.2 \%)$ & $2(4 \%)$ & 0 \\
\hline Community & $27(43.6 \%)$ & $19(38 \%)$ & $8(66.7 \%)$ \\
\hline
\end{tabular}

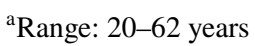

${ }^{b}$ Range: $13-120$ close contacts. 120 close contacts (43 students and 77 staff) were identified in a school where multiple cases emerged in the context of a large outbreak stemming from a single index case
Of the 56 index cases that had symptoms, the symptoms experienced were cough $(57.1 \%)$, rhinorrhoea $(55.3 \%)$, fatigue $(44.6 \%)$, sore throat $(44.6 \%)$, fever $(37.5 \%)$, headache $(37.5 \%)$, anosmia or ageusia $(23.2 \%)$, myalgia or arthralgia $(23.2 \%)$, dyspnoea $(16.1 \%)$, diarrhoea $(8.9 \%)$ and nausea or vomiting (3.6\%).

A total of 485 school close contacts were identified by contact tracing, $73.2 \%(n=355)$ of whom were students and $26.8 \%(n=130)$ of whom were staff (Table 2$)$. Of these 485 school close contacts, 20 tested positive for COVID-19, indicating an overall in-school transmission rate of $4.1 \%$. The positivity rate among student close contacts was $3.1 \%$, while the positivity rate among staff close contacts was $6.9 \%(p=0.07)$. These 20 cases arose from a total of 152 infectious school days, amounting to, on average, one case per 7.6 infectious school days.
Table 2 The COVID-19 positivity rate of student and staff close contacts in schools in HSE South, Ireland, 27 August-11 October 2020 $(n=485)$

\begin{tabular}{llclc}
\hline Close contacts & No. identified & $\begin{array}{l}\text { Positive COVID- } \\
19 \text { result (\%) }\end{array}$ & $\begin{array}{l}\text { 'Not Detected' } \\
\text { COVID-19 result (\%) }\end{array}$ & Unknown result (\%) \\
\hline Students & 355 & $11(3.1 \%)$ & $333(93.8 \%)$ & $11(3.1 \%)$ \\
Staff & 130 & $9(6.9 \%)$ & $119(91.6 \%)$ & $2(1.5 \%)$ \\
Total & 485 & $20(4.1 \%)^{*}$ & $452(93.2 \%)$ & $13(2.7 \%)$ \\
\hline
\end{tabular}

Source: CIDR, digital records of Dept PH HSE South and HSE Covid Care Tracker application

*A single outbreak in a special school accounted for 11 of those 20 cases 
Table 3 The burden of COVID19 due to in-school transmission of SARS-CoV-2 in HSE South, Ireland, 27 August-11 October 2020

\begin{tabular}{lllll}
\hline Role & Total cases & $\begin{array}{l}\text { School was direct } \\
\text { infection source }\end{array}$ & $\begin{array}{l}\text { School was indirect } \\
\text { infection source* }\end{array}$ & $\begin{array}{l}\text { Total infec- } \\
\text { tions due to } \\
\text { schools }\end{array}$ \\
\hline $\begin{array}{l}\text { Total } \\
\text { all ages })\end{array}$ & $1,614(100 \%)$ & $20(1.2 \%)$ & $16(1.0 \%)$ & $36(2.2 \%)$ \\
$\begin{array}{l}\text { Children } \\
(4-18 \text { years })\end{array}$ & $199(100 \%)$ & $11(5.5 \%)$ & $4(2.0 \%)$ & $15(7.5 \%)$ \\
$\begin{array}{l}\text { Adults } \\
(19-65 \text { years })\end{array}$ & $1,141(100 \%)$ & $9(0.8 \%)$ & $12(1.1 \%)$ & $21(1.8 \%)$ \\
\hline
\end{tabular}

Source: CIDR, digital records of Dept PH HSE South and HSE Covid Care Tracker application

*Infected outside of the school setting by a case infected in school
There were a high number of transmission events during a single outbreak in one special school. Excluding this atypical event gave an overall in-school transmission rate of $2.5 \%$, as opposed to $4.1 \%$. Furthermore, excluding this atypical event, the positivity rate among student close contacts was $2.2 \%$, and the positivity rate among staff close contacts was $3.8 \%(p=0.6)$.

Of the 20 close contacts who tested positive for COVID$19,55 \%(n=11)$ were infected in a single special school, $35 \%(n=7)$ were infected in four separate primary schools and $10 \%(n=2)$ were infected in two post-primary schools. Of these 20 cases, $11(55 \%)$ were symptomatic and $9(45 \%)$ were asymptomatic. Seven (77.8\%) of the 9 staff infected in school were symptomatic; only 4 (36.3\%) of the 11 students infected in school were symptomatic.

Of the 1614 cases of COVID-19 in HSE South during the observation period, only 20 (1.2\%) were directly infected in schools (Table 3). The 20 cases of COVID-19 caused by inschool transmission during the observation period, however, led to 16 further transmission events in total outside of the school setting. Therefore, schools both directly and indirectly accounted for 36 of 1614 (2.2\%) of all notified cases of COVID19 in HSE South during the first 6 weeks of the academic year.

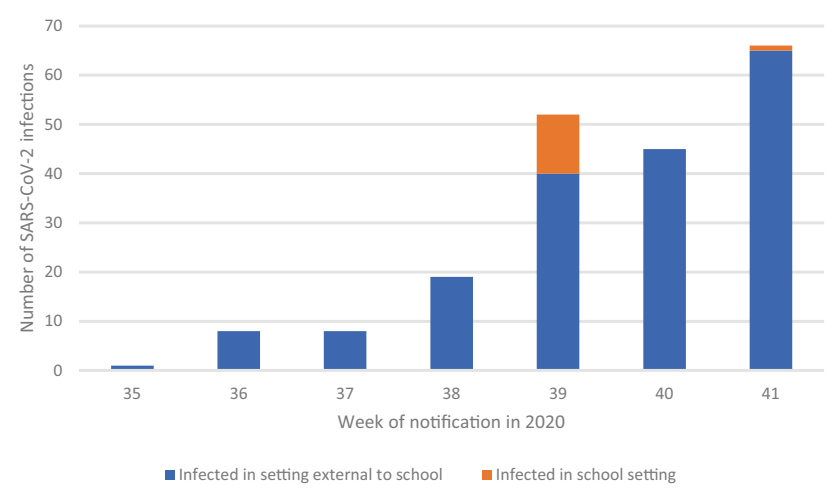

Source: CIDR; digital records of Dept PH; HSE Covid Care Tracker Application.

Fig. 1 Weekly number of notifications of COVID-19 in children aged 4-18 years by source of infection, Cork and Kerry, Ireland, 27 August-11 October $2020(n=199)$
Of the 199 cases of COVID-19 in school-going age children (i.e. 4-18 years) in HSE South during the observation period, schools accounted for $15(7.5 \%)$ cases (Fig. 1). Of the 1141 cases of COVID-19 in adults aged 19-65 years in HSE South during the observation period, schools accounted for 21 (1.8\%) cases (Fig. 2).

\section{Discussion}

This study investigated in-school transmission of SARSCoV-2 in primary, post-primary and special schools in HSE South during the first 6 weeks of the 2020-2021 academic year. Overall, it was found that the rate of in-school transmission of SARS-CoV-2 was low and that in-school transmission of SARS-CoV-2 did not contribute substantially to the burden of COVID-19 in the region during this time.

The role schools play in the overall transmission of SARS-CoV-2 is not yet fully understood [15]. The findings of this study demonstrate that the vast majority of close contacts identified in schools had 'not detected' test results for COVID-19. This is consistent with findings of

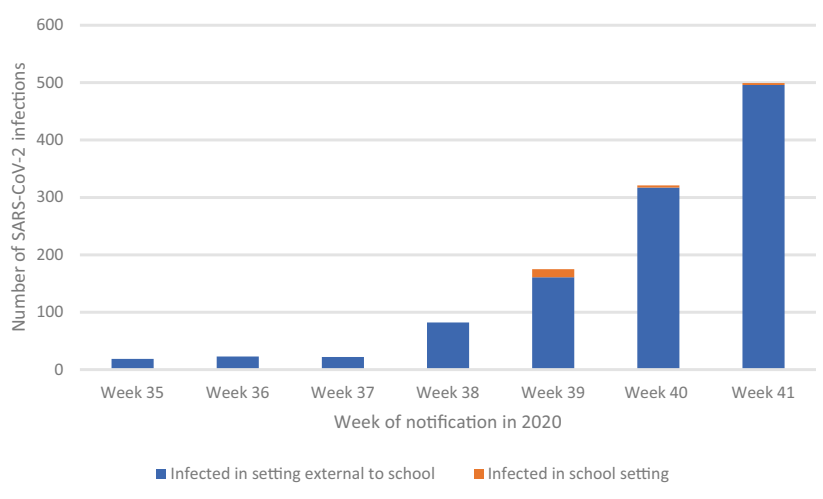

Source: CIDR; digital records of Dept PH; HSE Covid Care Tracker Application.

Fig. 2 Weekly number of notifications of COVID-19 in adults aged 19-65 years by source of infection, Cork and Kerry, Ireland, 27 August-11 October $2020(n=1141)$ 
other studies which have shown a low rate of transmission of SARS-CoV-2 in educational settings [16-19]. The finding that index cases spent on average 7.6 infectious days each in school before a further case emerged is somewhat surprising. It is noted, however, that a study of transmission of SARS-CoV-2 in schools and childcare facilities in Baden-Wurttemberg, Germany, which implemented similar IPC measures to those in Irish schools, estimated that one secondary case arose in schools and childcare facilities for every 25 infectious days spent by index cases in school [20].

By examining the COVID-19 test results of social and household contacts of cases infected at school and subsequently examining the tests results of their close contacts, and so on, the extent to which schools contributed to the overall burden of COVID-19 in HSE South over the observation period was determined with a high degree of confidence. Ultimately, schools were found to account for a very small proportion of the overall notified cases of COVID-19 in HSE South during this period. This finding is consistent with studies which have estimated that the reopening, or indeed closures, of schools has little effect on the incidence of COVID-19 [21, 22].

The first 6 weeks of the 2020-2021 academic year coincided with a period of low community transmission of SARS-CoV-2 in HSE South, with the 14-day incidence of COVID-19 remaining below 80 cases per 100,000 population for a significant part of the observation period [23]. This low level of community transmission allowed the transmission dynamics of SARS-CoV-2 in schools to be more clearly investigated. It could be asserted with a high degree of confidence that close contacts of a case in school, with no other apparent infection source, were infected in school, rather than in the community. While in-depth epidemiological investigations were carried out for all cases and helped to determine the direction of transmission in school and outside the school setting, unrecognised community transmission, however, cannot be fully ruled out in all cases. Whole-genome sequencing of epidemiologically linked school cases would have assisted with ruling this out, but was not performed.

The limitations of this study, however, must be acknowledged. Firstly, as the risk of school outbreaks of COVID-19 is associated with the incidence of COVID-19 in the wider community [24], our findings may not be generalizable to periods of high community transmission. Secondly, the study did not examine the association between risk of inschool transmission of SARS-CoV-2 and school type or certain school characteristics.

Notwithstanding its limitations, this study's findings contribute to the emerging evidence base regarding the extent to which SARS-CoV-2 is transmitted in schools. Further investigation into transmission dynamics of SARS-CoV-2 in schools, including during periods of high community transmission and in relation to special school settings, is needed.
Data availability All relevant data are published.

\section{Declarations}

Ethics approval Data were analysed as part of routine public health practice and not for research purposes. Therefore, ethics approval was not required.

\section{References}

1. Department of Education (2020) Covid-19 - statement from the Department of Education and Skills. Dublin, Ireland: Department of Education and Skills; [cited 3 Nov 2020]. Available from: https://www.education.ie/en/Press-Events/Press-Releases/2020press-releases/12-march-2020-statement-from-the-departmentof-education-and-skills.html

2. Department of Education (2020) Reopening our schools: the roadmap for the full return to school. Dublin, Ireland

3. Department of Education and Skills (2020) COVID-19 Response Plan for the safe and sustainable reopening of Post Primary Schools. Department of Education and Skills, Dublin, Ireland

4. Department of Education and Skills (2020) COVID-19 Response Plan for the safe and sustainable reopening of Primary and Special Schools. Department of Education and Skills, Dublin, Ireland

5. Office of the Clinical Director, Health Protection, HSE (2020) Schools pathway for Covid-19, the Public Health approach. Dublin, Ireland: Health Protection Surveillance Centre

6. Central Statistics Office (2017) Population at each census from 1841 to 2016 by county, sex and census year. Cork, Ireland: CSO; [cited 3 Nov 2020]. Available from: https://statbank.cso.ie/px/ pxeirestat/Statire/SelectVarVal/saveselections.asp

7. Central Statistics Office (2017) Census 2016 summary results part 1. Central Statistics Office, Dublin, Ireland

8. Central Statistics Office (2020) National schools by county, year and statistic. Dublin, Ireland, [cited 3 Nov 2020]. Available from: https://statbank.cso.ie/px/pxeirestat/Statire/SelectVarVal/ saveselections.asp

9. Central Statistics Office (2020) Second level schools and pupils by county, type of school, year and statistic. Dublin, Ireland CSO; [cited 3 Nov 2020]. Available from: https://statbank.cso.ie/px/ pxeirestat/Statire/SelectVarVal/saveselections.asp

10. Department of Education (2011) Special school list. Dublin, Ireland [cited 3 Nov 2020]. Available from: www.education. ie > epl_special_school_list_2010_2011

11. Department of Education (2020) School holiday dates. [cited 4 Nov 2020]. Available from: https://www.education.ie/en/ schools-colleges/information/school-holidays/

12. Health Information and Quality Authority (2020) HIQA publishes an evidence summary on the duration of infectiousness of COVID-19 patients [press release]

13. Health Protection Surveillance Centre (2016) Computerised Infectious Disease Reporting (CIDR) Dublin, Ireland: HPSC; [cited 3 Nov 2020]. Available from: https://www.hpsc.ie/cidr/

14. StataCorp (2017) Stata statistical software: Release 15. College Station, TX: StataCorp. LP

15. Viner RM, Russell SJ, Croker H et al (2020) School closure and management practices during coronavirus outbreaks including COVID-19: a rapid systematic review. Lancet Child Adolesc Health 4(5):397-404

16. Im Kampe EO, Lehfeld AS, Buda S et al (2020) Surveillance of COVID-19 school outbreaks, Germany, March to August 2020. Euro Surveill 25(38):09 
17. Macartney K, Quinn HE, Pillsbury AJ et al (2020) Transmission of SARS-CoV-2 in Australian educational settings: a prospective cohort study. Lancet Child Adolesc Health 4(11):807-816

18. Yung CF, Kam KQ, Nadua KD et al (2020) Novel coronavirus 2019 transmission risk in educational settings. Clin Infect Dis

19. Heavey L, Casey G, Kelly C et al (2020) No evidence of secondary transmission of COVID-19 from children attending school in Ireland, 2020. Euro Surveill 25(21):05

20. Ehrhardt J, Ekinci A, Krehl H et al (2020) Transmission of SARS$\mathrm{CoV}-2$ in children aged 0 to 19 years in childcare facilities and schools after their reopening in May 2020, Baden-Wurttemberg, Germany. Euro Surveill 25(36):09
21. Català M, Cardona PJ, Prats C et al (2020) Analysis and prediction of COVID-19 for EU-EFTA-UK and other countries. [cited 2 Dec 2020]. Available from: http://hdl.handle.net/2117/331969

22. Iwata K, Doi A, Miyakoshi C (2020) Was school closure effective in mitigating coronavirus disease 2019 (COVID-19)? Time series analysis using Bayesian inference. Int J Infect Dis 99:57-61

23. Health Protection Surveillance Centre (2020) Epidemiology of COVID-19 in Ireland - 14 day report. Dublin, Ireland: HPSC; 30 September 2020

24. Ismail S, Saliba V, Bernal J et al (2020) SARS-CoV-2 infection and transmission in educational settings: a prospective, crosssectional analysis of infection clusters and outbreaks in England. Lancet Infect Dis 